\title{
EFEKTIFITAS HYPNOTHERAPI TERHADAP PENURUNAN NYERI DISMENOREA PADA SISWI SMA
}

\author{
Nadi Aprilyadi ${ }^{1}$, H. Jhon Feri ${ }^{1}$,Indah Dewi Ridawati ${ }^{1}$ \\ ${ }^{1}$ Poltekkes Kemenkes Palembang Prodi Keperawatan Lubuklinggau \\ aprilyadi@gmail.com
}

\begin{abstract}
Abstrak
Dismenorea sering terjadi pada remaja. Di Indonesia prevalensi dismenore pada usia remaja sebesar $64,25 \%$ yang terdiri dari 54,89\% dismenore primer dan 9,36\% dismenore sekunder (Santoso, 2008). Secara farmakologi, penatalaksanaan adalah dengan pemberian obat-obat analgetik seperti golongan obat Nonsteroidal Antiinflammatory Drugs (NSAID) dapat meredakan nyeri. Salah satu pengobatan non farmakologi adalah dengan hipnoterapi yang merupakan aplikasi hipnosis dalam menyembuhkan masalah mental dan fisik (psikosomatis) seperti halnya nyeri, kecemasan, dll. Tujuan penelitian ini adalah untuk mengetahui pengaruh hipnoterapi terhadap nyeri dismenore pada siswi SMA PGRI I Lubuk Linggau. Penelitian ini merupakan penelitian pra eksperimen, dengan rancangan kuasi eksperimen one group pre and post test without control. Teknik sampel yang digunakan pada penelitian ini adalah Total Sampling sebanyak 17 responden. Instrumen yang digunakan dalam penelitian ini menggunakan quesioner penilaian nyeri Visual Analog Scale (VAS) dengan skala Numeric Rating Scale (NRS). Analisa univariat mayoritas siswi yang mengalami penurunan intensitas nyeri dismenore berusia 16- 17 tahun dan $100 \%$ responden mengalami penurunan intensitas nyeri dismenore setelah mendapatkan hipnoterapi, analisis bivariat dengan uji t-test didapatkan pengaruh yang signifikan Hipnoterapi terhadap penurunan intensitas nyeri dismenore ( value 0,000). Hipnoterapi disarankan untuk digunakan dalam penerapan asuhan keperawatan nyeri khususnya guna mengurangi intensitas nyeri dismenore.
\end{abstract}

Kata Kunci : Hipnoterapi, Dismenore

\begin{abstract}
The Effectiveness Of Hypnotherapy On Disease Of Diseases Of Dismenore In Female StudentSenior High School PGRI I Lubuklinggau.Dysmenorrhoea often occurs in adolescents. In Indonesia the prevalence of dysmenorrhea in adolescence is 64,25\% consisting of 54,89\% primary dysmenorrhea and 9,36\% secondary dysmenorrhea (Santoso, 2008). Pharmacologically management is by administering analgesic drugs such as the Nonsteroidal Anti Inflammatory Drugs (NSAID) group to relieve pain. One of the non-pharmacological treatments is hypnotherapy which is the application of hypnosis in curing mental and physical problems (psychosomatic) as well as pain, anxiety, etc.The purpose of this study was to determine the effect of hypnotherapy on dysmenorrhea pain in high school students PGRI I LubukLinggau. This is a pre experimental study, with a quasi-experimental one group pre and post test without control design. The sample technique used in this study is Total Sampling of 17 respondents. The instrument used in this study used Visual Analog Scale (VAS) visual pain assessment quesioner with Numeric Rating Scale scale (NRS). Univariate analysis of the majority of students who experienced decreased intensity of dysmenorrhea pain aged 16-17 years and 100\% of respondents experienced decreased intensity of dysmenorrhea pain after obtaining hypothotherapy, bivariate analysis with t-test test showed significant effect Hypnotherapy to decrease intensity of dysmenorrhea pain ( value 0,000) .Hypnotherapy is recommended for use in the application of pain nursing care especially to reduce the intensity of dysmenorrhea pain.
\end{abstract}

Keywords: Hypnotherapy, Dysmenorrhea

\section{Pendahuluan}

Dismenorea sering terjadi pada remaja. Studi longitudinal dari Swedia melaporkan dismenorea terjadi pada $90 \%$ wanita yang berusia kurang dari 19 tahun (French, 2005). Dismenorea adalah penyebab utama absen dan terganggu aktifitas lain. Hasil studi menunjukkan hampir $10 \%$ dari wanita dengan dismenorea mengalami tingkat ketidakhadiran 1 sampai 3 hari per bulan dalam bekerja karena dismenorea (Poureslami dan Ashtiani, 2001). 
Berdasarkan hasil penelitian Mahmudiono pada tahun 2011, angka kejadian dismenore primer pada remaja wanita yang berusia $14-19$ tahun di Indonesia sekitar $54,89 \%$. Hasil penelitian Novia pada tahun 2012 menunjukkan 84,4 $\%$ remaja usia 16 - 18 tahun di SMA St. Thomas 1 Medan mengalami dismenore. Dengan intensitas nyeri ringan $46,7 \%$, nyeri sedang $30,0 \%$, dan nyeri berat 23,3\%. (Hendarini, 2014). Dalam pelaksanaan tindakan keperawatan nyeri dapat dikurangi atau dihentikan dengan dua terapi yaitu terapi farmakologis dan non farmakologis. Terapi farmakologis dilakukan dengan cara pemberian obat analgesik, yang digunakan untuk memblok transmisi stimulus agar terjadinya perubahan persepsi dengan cara mengurangi kortikal terhadap nyeri. Sedangkan terapi non farmakologis dengan cara mengurangi faktor yang dapat menambah nyeri misalnya ketidakpercayaan, kesalahpahaman, ketakutan, kelelahan dan kebosanan, memodifikasi stimulus nyeri menggunakan teknik-teknik seperti teknik latihan penglihatan (menonton televisi, berbincang-bincang dengan orang lain, mendengarkan musik), teknik relaksasi (menarik napas dalam), dan stimulasi kulit (menggosok dengan halus pada bagian daerah nyeri, menggosok punggung, menggunakan air hangat dan dingin, memijat dengan air mengalir) (Hidayat, 2013). Tindakan non farmakologi lain untuk mengatasi nyeri, diantara nya yaitu Hipnoterapi, dalam hal ini perawat berperan dalam penanganan secara non farmakologis.

Hipnoterapi adalah salah satu cabang ilmu psikologis yang mempelajari manfaat sugesti untuk mengatasi masalah pikiran, perasaan, dan perilaku. Jika kita mengikuti hipnoterapi, kita akan dibimbing memasuki kondisi trance (relaksasi pikiran) agar pikiran kita siap menerima sugesti yang diberikan oleh hipnoterapis. (Muhammad, 2011). Penelitian yang dilakukan kepada 27 orang responden oleh
Astari dan Maliya (2010), menunjukkan bahwa sebelum diberi hipnoterapi, tidak terdapat responden yang tidak nyeri $(0 \%)$, responden yang merasa nyeri sedang sebanyak 23 responden $(85,2 \%)$ dan nyeri hebat sebanyak 4 responden $(14,8 \%)$. Setelah diberi hipnoterapi terjadi perubahan tingkat nyeri yang dirasakan responden, yaitu nyeri ringan sebanyak 23 responden $(88,9 \%)$ dan nyeri sedang sebanyak 3 responden $(11,1 \%)$.Helmi $\mathrm{F}$. dan Jenita $\mathrm{S}$. menyimpulkan bahwa terdapat pengaruh hipnoterapi terhadap penurunan skala nyeri dismenore. Terdapat dua Mekanisme yang menjelaskan hipnoterapi dapat menurunkan intensitas dismenore primer yaitu dengan pelepasan hormone endorphin sehingga memblok impuls nyeri dan dengan mengubah persepsi nyeri di kortek serebri (Helmi, 2016).

Berdasarkan studi pendahuluan di SMA PGRI I Lubuk Linggau para siswi sering mengalami dismenorea pada saat menstruasi yang kadang mengganggu aktivitas siswi. Dalam satu bulan sebanyak 10-16 siswi mengalami keluhan dismenorea saat menstruasi berlangsung. Hasil wawancara kepada tiga siswi baik kelas 1, 2 dan 3 diperoleh keterangan bahwa belum pernah dilakukan hypnotherapi untuk mengurangi nyeri dismenorea di SMA PGRI I Lubuk Linggau.

Dari uraian di atas maka penulis tertarik untuk meneliti mengenai perbedaan penurunan nyeri siswi SMA PGRI I Lubuk Linggau dalam penatalaksanaan hipnoterapi dismenorea. Dengan adanya penelitian ini diharapkan para siswi SMA PGRI I Lubuk Linggau memiliki alternatif pengobatan dismenorea dalam upaya mengurangi keluhan yang terjadi selama dismenorea.Berdasarkan latar belakang yang telah diuraikan di atas tujuan umum dari penelitian ini adalah untuk mengetahui perbedaan nyeri dismenorea sebelum dan setelah diberi hipnoterapi pada siswi SMA PGRI I Lubuk Linggau. 


\section{Metode}

Penelitian iniadalah penelitian kuantitatif dengan rancanganOne group Pretest-Posttestyang dilakukan di SMA PGRI I Lubuk Linggau pada bulan November Tahun 2017.Teknik pengambilan sampelmenggunakan total sampling, dengan kriteria inklusi berusia antara 13-20 tahun, belum pernah menikah, responden saat dismenorea berada di sekolah, responden sadar dan dapat diajak komunikasi secara aktif, bersedia menandatangani lembar persetujuan penelitian (informed consent). Kriteria eksklusi: responden dengan gangguan kesadaran, memiliki penyakit akut lain saat diberi hipnoterapi.

Pada penelitian ini jumlah sampel sebanyak 17 responden, dan analisis data menggunakan uji beda dua mean paired $t$ test untuk melihat perbedaan penurunan nyeri dismenorea siswa, sebelum dan sesudah mendapatkan hipnoterapi. Peneliti ingin membandingkan efektifitas hipnoterapi terhadap penurunan nyeri dismenorea.

Instrumen yang digunakan untuk memperoleh data tentang nyeri adalah skala nyeri NRS (Numeric Rating Scale). NRS adalah skala nyeri untuk menilai kualitas nyeri dimulai dari angka 0 yang menunjukkan tidak nyeri dan angka 10 yang menunjukkan nyeri sekali.Sebelum tes dikenakan pada responden, dilakukan uji validitas dan realibilitas instrumen yang dilaksanakan pada 30 orang siswi SMA PGRI I Lubuklinggau.Pada penelitian ini Hipnoterapi dilakukan untuk menurunkan intensitas nyeri dismenorea yang dilakukan sebanyak dua hari berturut-turut, masingmasing selama 45 menit.

\section{Hasil}

Umur responden disajikan pada gambar 1. Gambar 1 menunjukkan mayoritas kelompok umur 16-17 tahun sebanyak 13 responden (76,5\%). Umur adalah usia individu yang terhitung mulai saat dilahirkan sampai saat berulang tahun. Hasil penelitian ini menunjukkan bahwa kelompok umur 16-17 tahun lebih banyak mengalami dismenore.

Gambar 1.

Distribusi Responden Berdasarkan Umur 


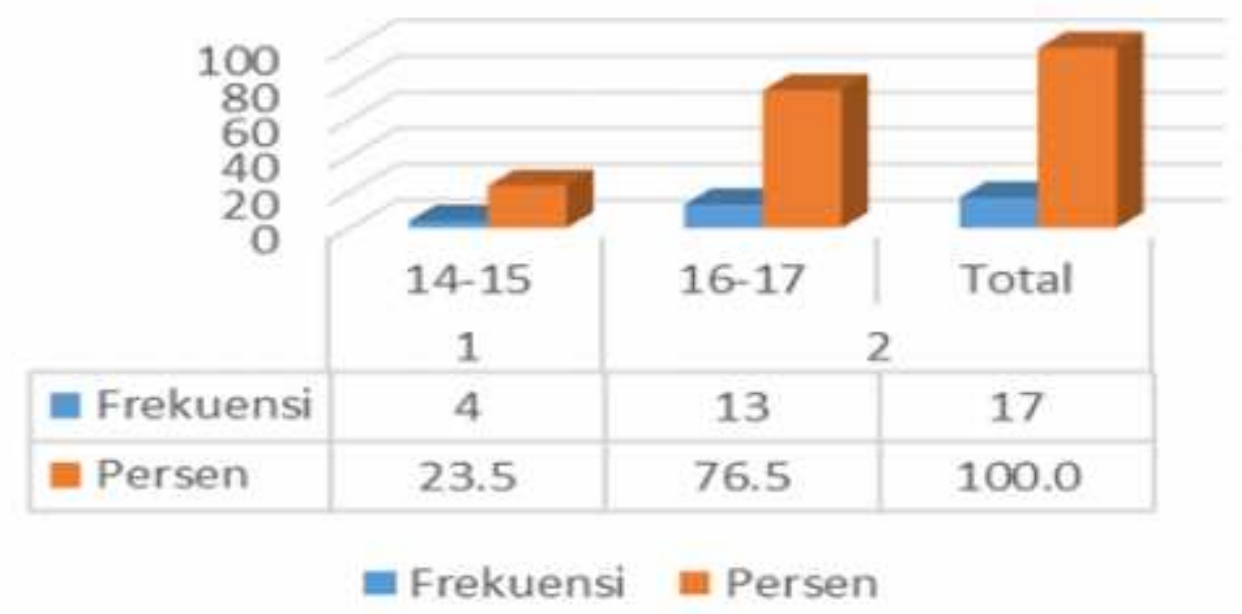

Gambar 2.

Distribusi Responden Berdasarkan Skala Nyeri Pre \& Post Perlakuan Hari I (Pertama)

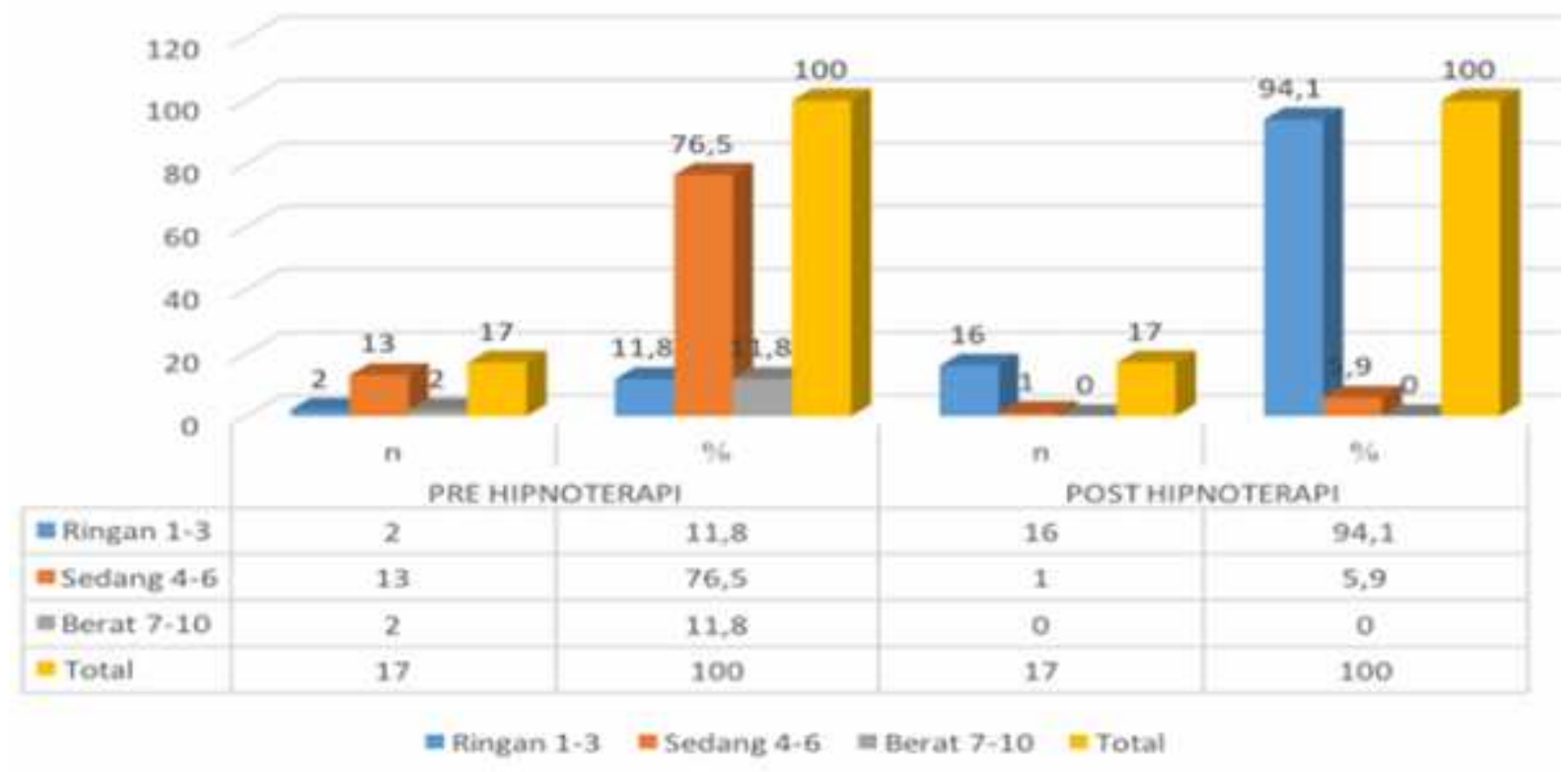

Berdasarkan gambar 2 diatas, diketahui bahwa dari 17 responden penelitian, pada saat Pre Hipnoterapi yang menyatakan nyeri berat terkontrol sebanyak 2 orang $(11,8 \%)$, nyeri sedang sebanyak 13 orang $(76,5 \%)$, nyeri ringan sebanyak 2 orang $(11,8 \%)$. Sedangkan pada saat post Hipnoterapi yang menyatakan nyeri berat terkontrol sebanyak 0 orang $(0 \%)$, nyeri sedang sebanyak 1 orang $(5,9 \%)$, dan yang menyatakan nyeri ringan sebanyak 16 orang $(94,1 \%)$. Hal ini menunjukkan bahwa sebagian besar responden mengalami penurunan intensitas nyeri.
Berdasarkan gambar 3 diatas, diketahui bahwa dari 17 responden sesudah dilakukan hipnoterapi pada hari pertama, yang menyatakan nyeri ringan sebanyak 4 orang $(23,5 \%)$, nyeri sedang sebanyak 11 orang $(64,7 \%)$, nyeri berat terkontrol sebanyak 2 orang $(11,8 \%)$. Hal ini menunjukkan bahwa hampir sebagian besar $(64,7 \%)$ responden menyatakan nyeri sedang sebelum mendapatkan hipnoterapi hari kedua. Sedangkan hasil pada saat post hipnoterapi hari kedua ini didapatkan bahwa bahwa dari 17 responden, kesemuanya menyatakan nyeri yang dirasakan berada pada skala ringan 
(100\%). Hal ini menunjukkan bahwa terjadi penurunan intensitas nyeri yang sangat berarti terhadap 17 responden tersebut.

Gambar 3.

Distribusi Responden Berdasarkan Skala Nyeri Pre \& Post Perlakuan Hari II (Kedua)

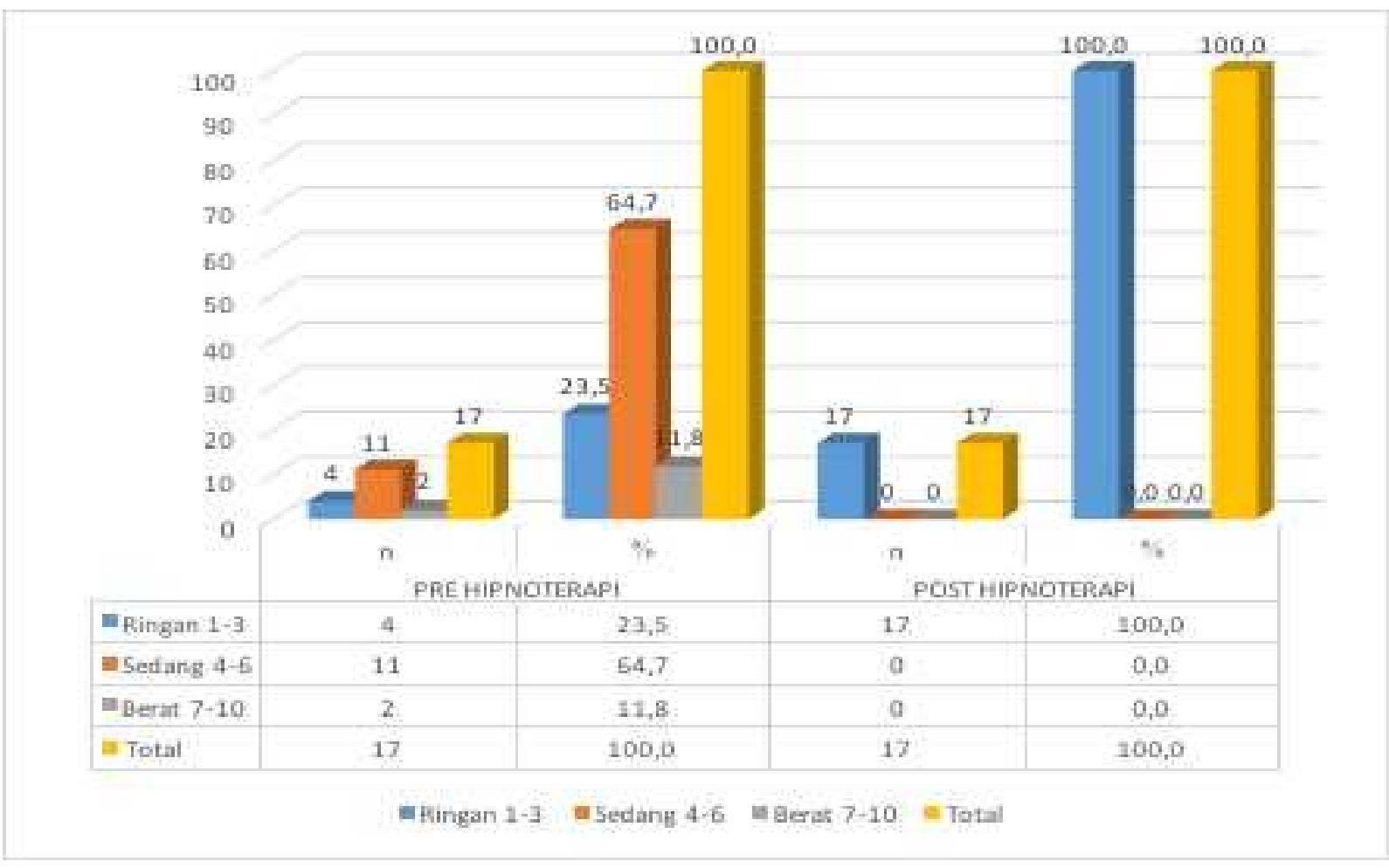

Tabel 1

Perbedaan Intensitas Nyeri Dismenore (Nrs) Pre dan Post Hipnoterapi Responden $(n=17)$

\begin{tabular}{clccccc}
\hline No & Intensitas Nyeri (Nrs) & $\mathrm{n}$ & Mean & SD & SE & $P$ Value \\
\hline 1 & Hari Pertama & 17 & 0,94 & 0,500 & 0,121 & 0,000 \\
& Pre & 17 & 0,429 & 0,243 & 0,059 & \\
& Post & & & & & \\
2 & Hari Kedua & 17 & 0,882 & 0,600 & 0,146 & 0,000 \\
& Pre & 17 & 0,600 & 0,000 & 0,000 & \\
& Post &
\end{tabular}

Berdasarkan tabel 4.1 didapatkan bahwa selisih mean antara pre dan post Hipnoterapi hari pertama 0,51. Sedangkan selisih mean antara pre dan post Hipnoterapi hari kedua 0,28. Hasil uji statistik dengan uji beda dua mean paired $t$ test didapatkan keduanya hasil $p$ value 0,000. Berarti hipnoterapi berpengaruh dalam menurunkan intensitas nyeri dismenore pada siswi SMA PGRI 1 Lubuklinggau.

\section{Pembahasan}

Hasil penelitian gambar 1 diketahui mayoritas kelompok responden berumur 16-17 tahun (76,5\%). Berarti responden Nyeri Dismenore adalah tergolong remaja. Menurut peneliti, usia responden dalam penelitian ini termasuk dalam kategori remaja pertengahan berada pada rentang usia 15-17 tahun. Hasil penelitian ini sesuai dengan teori bahwa usia dapat mempengaruhi tingkat nyeri dismenore, pada umumnya terjadi pada usia 15-17 tahun, selain itu pada usia tersebut terjadi 
perkembangan organ-organ reproduksi dan perubahan hormonal yang signifikan.

Hasil penelitian ini menunjukkan bahwa kelompok umur 16-17 tahun lebih banyak mengalami dismenore. Bila dihubungkan dengan hasil pada gambar 1 dapat dianalisis bahwa usia 16-17 tahun seorang wanita berisiko untuk menderita dismenore primer. Hasil penelitian ini sesuai dengan apa yang dikemukakan Junizar (2004), bahwa dismenore primer umumnya terjadi pada usia 15-30 tahun dan sering terjadi pada usia 15-25 tahun yang kemudian hilang pada usia akhir 20an atau awal 30-an.

Penelitian membuktikan bahwa dismenore primer disebabkan karena adanya prostaglandin $F 2 \alpha$, yang merupakan stimulan miometrium poten dan vasokonstriktor pada endometrium. Kadar prostaglandin yang meningkat selalu ditemui pada wanita yang mengalami dismenore dan tentu saja berkaitan erat dengan derajat nyeri yang ditimbulkan. Peningkatan kadar ini dapat mencapai 3 kali dimulai dari fase proliferatif hingga fase luteal, dan bahkan makin bertambah ketika menstruasi. Peningkatan kadar prostaglandin inilah yang meningkatkan tonus miometrium dan kontraksi uterus yang berlebihan. Adapun hormon yang dihasilkan pituitari posterior yaitu vasopresin yang terlibat dalam penurunan aliran menstrual dan terjadinya dismenore (Karim, 2013).

Sesuai dengan teori bahwa lamanya menstruasi (>7hari) dapat mempengaruhi tingkat nyeri dismenore sehingga menimbulkan adanya kontraksi uterus, terjadi lebih lama mengakibatkan uterus lebih sering berkontraksi, dan semakin banyak prostaglandin yang di keluarkan. Produksi prostaglandin yang berlebihan menimbulkan rasa nyeri, sedangkan kontraksi uterus yang terus menerus menyebabkan suplai darah ke uterus terhenti dan terjadi dismenore. Selain itu yang paling mempengaruhi tingkat nyeri dismenore adalah usia menarche yang terlalu dini, dimana organ - organ reproduksi belum berkembang secara maksimal dan masih terjadi penyempitan pada leher rahim, maka akan timbul rasa sakit pada saat menstruasi, karena organ reproduksi wanita belum berfungsi secara maksimal.

Dengan demikian maka asumsi peneliti bahwa nyeri yang dialami oleh responden yaitu nyeri sedang merupakan sesuatu yang fisiologis atau normal, namun meskipun sesuatu yang normal bukan berarti boleh dibiarkan karena nyeri haid yang tidak mendapatkan penanganan akan berdampak lebih buruk bagi kesehatan siswi dan bahkan dapat mengganggu aktivitas belajar di sekolah.

Hal ini sejalan dengan yang dikemukakan oleh teori yang menyatakan bahwa nyeri haid dengan intensitas nyeri sedang memerlukan obat-obatan untuk menghilangkan nyeri tersebut tetapi tidak perlu meninggalkan pekerjaannya sedangkan nyeri haid dengan intensitas nyeri berat memerlukan obat-obatan, istirahat dan dapat mengganggu aktifitas sehari-hari (Manuaba,2009).

Kejadian dismenore primer sangat dipengaruhi oleh usia wanita. Rasa sakit yang dirasakan beberapa hari sebelum menstruasi dan saat menstruasi biasanya karena meningkatnya sekresi hormon prostaglandin. Semakin tua umur seseorang, semakin sering ia mengalami menstruasi dan semakin lebar leher rahim maka sekresi hormon prostaglandin akan semakin berkurang. Selain itu, dismenore primer nantinya akan hilang dengan makin menurunnya fungsi saraf rahim akibat penuaan (www. medicastore.com, 2006). Dalam teori Junizar (2004) dijelaskan bahwa dismenore primer nantinya akan hilang pada usia akhir 20-an atau awal 30an.

Hasil penelitian ini sedikit berbeda dengan teori yang ada. Disebutkan dalam teori, insiden tertinggi dismenore primer biasanya pada usia akhir 20-an dan awal 30-an, dan dari hasil penelitian ini didapatkan dismenore primer paling 
banyak terjadi pada wanita dengan golongan umur 16-17 Tahun.

\section{Efektifitas Hipnoterapi Terhadap Penurunan Intensitas Nyeri (Pre dan Post Perlakuan)}

Berdasarkan penelitian pada hari pertama sebelum dilakukan hipnoterapi sebagian besar remaja putri di SMA PGRI 1 Lubuklinggau menyatakan nyeri sedang pada saat mengalami haid (76,5\%). Adapun responden yang mengalami nyeri berat sebanyak 2 orang, nyeri sedang 13 orang, dan nyeri ringan sebanyak 2 orang.

Setelah dilakukan Hipnoterapi pada 17 orang responden tersebut, terjadi penurunan intensitas nyeri dimana responden yang mengalami nyeri berat menjadi 0 orang, yang mengalami nyeri sedang turun menjadi 0 orang. Sehingga dari hasil penelitian menunjukkan bahwa sebagian besar siswi SMA PGRI 1 Lubuklinggau setelah melaksanakan hipnoterapi menyatakan nyeri ringan $(94,1 \%)$. Sedangkan hasil penelitian pada hari kedua, dari 17 responden, yang menyatakan nyeri ringan sebanyak 4 orang $(23,5 \%)$, nyeri sedang sebanyak 11 orang $(64,7 \%)$, nyeri berat terkontrol sebanyak 2 orang $(11,8 \%)$. Hal ini menunjukkan bahwa hampir sebagian besar $(64,7 \%)$ responden menyatakan nyeri sedang sebelum mendapatkan hipnoterapi hari kedua. Sedangkan hasil pada saat post hipnoterapi hari kedua ini didapatkan bahwa bahwa dari 17 responden, kesemuanya menyatakan nyeri yang dirasakan berada pada skala ringan (100\%). Hal ini menunjukkan bahwa terjadi penurunan intensitas nyeri yang sangat berarti terhadap 17 responden tersebut. Sehingga dari hasil penelitian menunjukkan bahwa kesemua siswi SMA PGRI 1 Lubuklinggau yang telah melaksanakan hipnoterapi menyatakan nyeri ringan $(100 \%)$.

Hasil pada tabel.1 uji statistik dengan uji beda dua mean paired t test didapatkan hasil $p$ value 0,000 . Hal ini menunjukkan efektifitas Hipnoterapi terhadap penurunan intensitas nyeri terbukti berhasil dengan baik. Adanya penurunan atau perubahan tingkat nyeri hal ini berarti bahwa perlakukan hipnoterapi yang dilaksanakan dengan baik akan mampu mengatasi nyeri pada saat haid. Hipnoterapi adalah penggunaan teknik hipnotis secara medis, atau penggunaan teknik relaksasi dalam, yang terutama ditunjukkan untuk mengobati masalah yang timbul akibat faktor psikologis, seperti mengurangi rasa nyeri atau mengubah perilaku. Misalnya, perilaku ketergantungan obat, ketergantungan merokok, penurunan berat badan dan enuresis. Praktisi menggunakan keterampilan konseling yang canggih yang dapat menimbulkan keadaan hipnotik pada klien atau dapat mengajarkan kepada mereka cara menimbulkan hipnosis(Andrew,2009).

Hasil penelitian menunjukkan bahwa terdapat hubungan teknik hipnoterapi terhadap penurunan tingkat nyeri haid pada siswi SMA PGRI 1 Lubuklinggau. Hal ini terbukti dari adanya perubahan tingkat nyeri pada siswi yang melaksanakan hipnoterapi. Berdasarkan hasil uji hipotesis tersebut dapat disimpulkan bahwa terdapat hasil yang signifikan dan bermakna dalam penurunan intensitas nyeri yang dialami responden. Adanya perbedaan nilai significancy dapat disimpulkan bahwa teknik hipnoterapi efektif terhadap penurunan tingkat nyeri haid.

Dismenore pada remaja harus ditangani meskipun hanya dengan pengobatan sendiri atau non farmakologi, pengobatan sederhana yang dapat dilakukan dengan menggunakan teknik relaksasi dan distraksi seperti pengalihan nyeri dengan menarik nafas panjang, mendengarkan musik, membaca buku ataupun melakukan kegiatan yang disukai. Teknik relaksasi melalui olah nafas merupakan salah satu keadaan yang mampu merangsang tubuh untuk membentuk sistem penekanan nyeri yang akhirnya menyebabkan penurunan nyeri. Disamping itu juga bermanfaat untuk pengobatan penyakit dari dalam tubuh 
meningkatkan kemampuan fisik keseimbangan tubuh dan pikiran, karena olah nafas dianggap membuat tubuh menjadi relaks sehingga berdampak kepada keseimbangan tubuh dan pengontrolan tekanan. Pada teknik relaksasi selain dapat mengurangi intensitas nyeri juga dapat meningkatkan ventilasi paru dan dapat meningkatkan oksigenasi darah (Dian,2011)

Salah satu teknik relaksasi nonfarmakologi dan terapi yang dapat dilakukan di Indonesia adalah Hipnoterapi, karena dengan melakukan teknik hipnoterapi dapat menghasilkan rasa nyaman sehingga rasa nyaman tersebut dapat merangsang hormon endorfin yang dapat menekan rasa nyeri seseorang. Pikiran sadar bisa mengandung semua unsur dari proses yang secara tradisional disebut sebagai "fenomena trans". Kunci dari hypnosis adalah adanya kekuatan sugesti atau keyakinan terhadap sesuatu hal yang positif yang muncul berdasarkan pada konsep dalam pikiran, sehingga akan memberikan energi positif bagi suatu tindakan yang dilakukan.

Saat pemberian hypnoterapi, responden dibimbing untuk melakukan imajinasi sehingga mempengaruhi kerja otak, gelombang otak terdiri dari gelombang beta yaitu gelombang otak yang paling umum dan frekuensinya paling tinggi dimana kondisi kerja otak dalam keadaan sadar untuk menjaga pikiran tetap terfokus kemudian menjadi gelombang alpha yaitu gelombang otak yang frekuensinya sedikit lebih lambat dibanding beta dimana kondisi kerja otak rileks dan santai, alfa merupakan jembatan penghubung antara pikiran sadar dan bawah sadar, sedangkan theta yaitu gelombang otak yang dihasilkan oleh pikiran bawah sadar dan terjadi pada saat seseorang mengalami keadaan sangat rilaks atau sangat mengantuk, pada kondisi peralihan gelombang otak tersebut akan menghasilkan tubuh menjadi rileks sehingga dapat melancarkan volume darah dan oksigenasi ke otak dan menghasilkan hormon endorfin yang dapat menghambat impuls nyeri sehingga seseorang menjadi rileks.

Efek relaksasi hipnoterapi langsung terlihat pada saat responden sedang dalam keadaan kondisi trance yang dalam yaitu responden terlihat santai, tenang dan rileks, bahkan ada beberapa responden tampak tertidur selama terapi hipnosis dan dapat mengikuti sesi terapi sampai selesai dengan penuh konsentrasi. Saat dalam kondisi rileks, perhatian responden terhadap nyeri teralihkan sehingga persepsi nyeri dan respon terhadap nyeri berubah, nyeri yang dirasakan menurun sampai dengan hilang. Tidak ada efek negatif yang merugikan responden. Hampir semua mengatakan suasana hati menjadi lebih nyaman, tenang dan rileks. Kajian inti dari hipnosis adalah berpijak pada asumsi dasar bahwa mind control dapat dicoba diterapkan dalam kegiatan intervensi pembedahan jaringan. Hal inilah yang disebut hypnoanesthesia. Keberhasilan menerapkan metode metode hipnoterapi dalam mengurangi bahkan menghilangkan rasa nyeri (hypnoanesthesi), penggunaan metode ini mengakibatkan berkurangnya bahkan menghilangkan rasa nyeri yang di alami tubuh manusia sebagai respon terhadap suatu trauma ataupun adanya intervensi terhadap jaringan.

Penelitian Ginandes, membuktikan hipnoterapi juga bisa digunakan untuk meredakan nyeri, melancarkan pernapasan, sertamengatasi gangguan pencernaan. Dengan hipnoterapi, dapat meningkatkan kadar endorphin dalam tubuh. Endorphin adalah hormon yang dihasilkan tubuh pada saat rileks atau tenang. Hal tersebut dapat digunakan untuk mengurangi rasa nyeri (Setyono,2011).

\section{Simpulan dan Saran}

Hasil penelitian dapat disimpulkan bahwaEfektifitas Hipnoterapi Terhadap Penurunan Nyeri Dismenorea Pada Siswi SMA PGRI 1 Lubuklinggau Tahun 2017 menunjukan hasil yang sangat baik. Bagi Institusi Pendidikan diharapkan dapat 
menyadari dan mengaplikasikan penerapan terapi keperawatan komplementer lain yang konsisten dan sesuai dengan teori yang ada, agar klien dapat memperoleh pelayanan yang komprehensif,meliputi bio, psiko, sosial, spiritualdan hasil penelitian ini dapat digunakan sebagai dasar pengembangan model Hipnoterapi dan terapi komplementer lainnya dalam menangani klien yang mengalami dismenore. Melihat adanya manfaat hipnoterapi bagi penurunan nyeri haid maka setiap remaja perlu mengetahui hipnoterapi ini sebagai salah satu alternatif yang dapat ditempuh oleh remaja untuk mengatasi nyeri pada saat haid dan petugas kesehatan dapat melakukan penyuluhan ke sekolah-sekolah mengenai hipnoterapi ini.

\section{Daftar Pustaka}

Arif, Antonius. (2011). The Handbook Of Hypnoterapy Scripts \& Strategies. Jakarta : Kompas Gramedia.

Budi, P. P.\& Rizali, Erwin. (2010). Cara Cepat Menguasai Hypno Healing Hipnosis untuk Penyembuhan. Yogyakarta : Grafina Mediacipta Cv.

Andarmoyo,S. (2013). Konsep \& Proses Keperawatan Nyeri.Jogjakarta : ArRuzz.

Asmadi. (2008). Teknik Prosedural Keperawatan : Konsep dan Aplikasi Kebutuhan Dasar Klien. Jakarta : Salemba Medika.

Dobson, James. (2006). Preparing for adolense.California : Vision House.

Efendi, Ferrry \& Makhfudli. (2009). Keperawatan Kesehatan Komunitas : Teori dan Praktik dalam Keperawatan. Jakarta : Salemba Medika.

Helmi, F. \& Jenita, S. (2016). Pengaruh Hipnoterapi terhadap Disemnore Primer pada Siswi Sekolah
Menengah Pertama. JKA.2016; 3(1): 69-75.

Hidayat, A. Alimul. (2013). Pengantar Kebutuhan Dasar Manusia-Aplikasi Konsep dan Proses Keperawatan. Jakarta : Salemba Medika.

Hutabarat, M., Permana,Rahma \& Masud, Mahzhuranni. (2010). 24 Kreasi Unik Kamar Remaja. Jakarta : Penebar Swadaya.

Judha, M.\& Sudiarti. (2012). Teori Pengukuran Nyeri dan Nyeri Persalinan. Yogyakarta : Nuha Medika.

Kumalasari, Intan \& Andhyantoro, Iwan. (2014). Kesehatan Reproduksi untuk Mahasiswa Kebidanan dan Keperawatan. Jakarta : Salemba Medika.

Lukman, N. Nurma. (2012). Asuhan Keperawatan Pada Klien Dengan Gangguan Sistem Muskuloskeletal. Jakarta : Salemba Medika.

Masjoer, Arif, dkk. (2001). Kapita Selekta Kedokteran Edisi Ketiga Jilid 1. Jakarta : Media Aesculapius.

Muhammad, As'adi. (2011). Melakukan Hinoterapi agar Daya Ingat Anda Sekuat Cakram. Yogyakarta : DIVA Press.

Muttaqin, Arif. (2008). Buku Ajar Asuhan Keperawatan Klien dengan Gangguan sistem persarafan. Jakarta : Salemba Medika.

Monks, F. J., Knoers, Haditomo. (2002). Psikologi Perkembangan : Pengantar dalam Berbagai Bagiannya. Yogyakarta : Gadjah Mada University Press. 
Proverawati, Atikah. (2009). Menstruasi Pertama Penuh Makna. Yogyakarta : Nuha Medika.

Saryono., Widianti, A. Tri. (2011). Cacatan Kuliah Kebutuhan Dasar Manusia (KDM). Jogjakarta : Nuha Medika.

Setiyohadi, Bambang, dkk. (2006). Ilmu Penyakit dalam. Jakarta : FKUI.

Smeltzer, Suzanne, C. (2001). Buku Ajar Keperawtan Medikal Bedah. Brunner \& Suddarth. Edisi 8. Jakarta : EGC.

Suwandi, Awie. (2010).Turbo Hipnotis : Rahasia Belajar Instan \& Aplikasi Hipnotis Praktis. Jakarta : PT Gramedia Pustaka Utama.

Tambayong, Jan. (2000). Patofisiologi untuk keperawatan. Jakaarta : EGC.

Tarwoto, dkk. (2010). Kesehatan Remaja : Problem dan Solusinya. Jakarta : Salemba Medika.

Toy, Harun, et al. (2016). Autistic traits in women with primary dysmenorrhea: a case-control study. Neuropsychiatric Disease and Treatment 2016:12 2319-2325.

Wong, Willy., Andri, H. (2009). Dahsyatnya Hipnosis. Jakarta : Visimedia.

Yulaikhah, Lily. (2008). Kehamilan : Seri Asuh Kebidanan. Jakart a: EGC. 